\section{People with learning disabilities and specialist services}

\author{
J. Owens, ${ }^{1}$ T. A. Dyer ${ }^{2}$ and K. Mistry ${ }^{3}$
}

IN BRIEF

- Raises concerns regarding the provision of specialist services for people with learning disabilities.

- Discusses the importance of including enhanced payments for general dental practitioners to allow for extra time necessary for care.

- Suggests a model of access for primary care organisations when commissioning dental services.

Valuing people and Valuing people's oral health ${ }^{2}$ both advocate choice and inclusion for people with learning disabilities. Research suggests that services and policy and guidance, while prescriptive and available, have not been effective in reducing oral health inequalities for people with learning disabilities. There is a risk that specialist services led by newly created consultants in special care dentistry may have the unintended effect of reducing choice if general dental practitioners are encouraged to refer all those with learning disabilities. A modified model of access is proposed that primary care organisations could use as a commissioning tool for dental contracts to facilitate choice and maximise involvement in oral health care for those with learning disabilities.

\section{Background}

In the UK, over 985,000 adults are registered as having a learning disability; 796,000 are aged 20 or over yet only $20 \%$ of them are known to the learning disability services. By 2021 it is predicted that there will be more than one million people with learning disabilities in the UK. ${ }^{3}$ In light of the recent debates around specialist services for people with disabilities in the dental literature, ${ }^{4-8}$ this predicted increase has implications for the delivery of services in the UK.

Valuing people ${ }^{1}$ was written with the key principles of Rights, Choice, Independence and Inclusion at its heart. Its origins came from the historical omission of people with learning disabilities from health policy. Its aim was to ensure that people with learning disabilities are not excluded from their choice of services so that their rights and dignity of independence are maintained and wherever possible they are able to access the same services as people without disabilities. Valuing people's oral

\footnotetext{
${ }^{1 *-3}$ Department of Oral Health and Development, University of Sheffield, School of Clinical Dentistry, Claremont Crescent, Sheffield, S10 2TA

${ }^{*}$ Correspondence to: Dr Janine Owens

Email: jan.owens@sheffield.ac.uk
}

\section{Refereed Paper}

Accepted 1 February 2010

DOI: $10.1038 /$ sj.bdj.2010.204

${ }^{\oplus}$ British Dental Journal 2010; 208: 203-205 health ${ }^{2}$ builds on Valuing people using the same principles, but was also designed to complement Choosing better oral health ${ }^{9}$ which was written to inform and influence the emerging commissioning role of the primary care organisations (PCOs) and improve services for people with disabilities. Valuing people's oral health acknowledges that applying a one-sizefits-all approach is not useful for adults and children with disabilities when trying to improve oral health and increasing choice is a necessity. Furthermore, it envisages general dental practices as 'a focal point of a fully integrated preventive care pathway' with a 'need to ensure that the local dental practice is available and accessible to those who do not require specialist care routinely' [Our emphasis] (p 25).

In a recent paper ${ }^{4}$ Gallagher and Fiske set out the professional challenges for special care dentistry. One of the key challenges is how NHS dentistry is now provided with the introduction of the new contract, and the change to local commissioning of dentistry through PCOs. In tandem with these changes are the development of a speciality in special care dentistry and the opening of a Specialist List in October 2008,5,6

\section{Definitions of disability and the Steele report}

The definition of disability as identified by the Joint Advisory Committee for Special
Care Dentistry (JACSD) ${ }^{5}$ is: 'Individuals and groups in society who have a physical, sensory, intellectual, mental, medical, emotional or social impairment or disability or more often a combination of a number of these factors.' In attempting to be inclusive, this definition could be interpreted as implying that people with a wide range of impairments are a homogenous group. As well as unintentionally disabling some people with impairments, it also suggests that all could fall under the remit of special care dentistry. While we agree that a speciality for special care dentistry is timely and much needed, we also echo Gallagher and Fiske's assertion that 'All people with disability should have access to NHS primary dental care. ${ }^{5}$ This implies that, as well as specialist services, provision should come from non-specialist general dental and salaried dental services. The Steele report ${ }^{8}$ identifies that access to care is a problem for people with disabilities and recommends that dental contracts are developed '....with much clearer incentives for improving health, improving access and improving quality' ( 7 ). While we fully support the aspiration to improve health, access and quality for all, the wording of the Steele report and the JACSCD definition of disability taken together could be construed as meaning that all people with disabilities should be cared for by specialist services. The risk is 
a reduction of choice of services for people with learning disabilities in particular if practitioners are encouraged to refer to specialist services all patients perceived to fall within it. This is of particular concern for such groups when need for care is often not expressed as demand and when they are often unable to choose.

The definition of a learning disability in Valuing people is: 'the presence of a significantly reduced ability to understand new or complex information, to learn new skills (impaired intelligence), with a reduced ability to cope independently (impaired social functioning); which started before adulthood, with a lasting effect on development.'

The International Classification of Mental and Behavioural Disorders ${ }^{10}$ categorises people with learning difficulties in terms of their measured level of 'intelligence' or Intelligence Quotient (IQ). For example, categorisation of a learning difficulty (disability), according to the world of medicine, means an IQ of 50-69 (mild), 35-49 (moderate), 20-34 (severe) and less than 20 (profound), alongside detailed clinical descriptions of each category. Any IQ measurement above 70 is within 'normal' limits. Even though Valuing people and various other authors ${ }^{11,12}$ dislike these definitions because diagnosing a person with learning disabilities separates them from the 'normal' population, and IQ alone is not a sufficient reason for deciding whether individuals should be provided with additional health and social care support, for the purposes of this paper it is probably useful to use these categorisations to illustrate which categories cause the authors concern. People with moderate/severe to profound impairments should have a specialist dental service because they are most likely to need one-to-one care and support, and are more likely to have higher needs. Whereas not all people with mild to borderline moderate learning disabilities will necessarily need specialist dental care. There appears to be an argument for the provision of case by case consideration and not lumping people together under one category.

One way of ensuring that a dental contract is developed with clearer incentives with the inclusion of discretionary payments for non-salaried dentists to allow for the extra time required when working with people with learning disabilities. ${ }^{13-15}$ Such an approach could be evaluated in a Steele demonstration pilot.

One example of the importance of allowing for extra time is for the care of some people with autistic spectrum disorders where many visits may be needed before an individual can sit in the chair. A visit to the dentist can be especially traumatic because of different factors such as anxiety related to change in environment: lights, different noises, people, ways of dressing, ${ }^{16}$ tactile and sensory issues, ${ }^{17}$ a lack of understanding about the purpose of the visit and importance of oral health, ${ }^{17}$ and because of the nature of dental treatment (even if it is only a check up) as an invasion of body space. ${ }^{17}$ Once these factors have been successfully addressed there are few reasons why dental treatment cannot proceed as for patients without autism spectrum disorders and in a general practice setting.

\section{Ensuring access to quality care}

If those with learning disabilities are to have access to quality services, what factors should be considered? As for access to general healthcare, different authors have suggested that access comprises more than just physical access for those with learning disabilities. ${ }^{18,19}$ In dentistry, Dougall and Fiske, ${ }^{20}$ conceptualised access to care as comprising four key dimensions:

- Access to the building

- Access to the dental surgery

- Access to the dental chair

- Access to the mouth.

However, for Penchansky and Thomas, ${ }^{21}$ the concept of access is more complex. Their dimensions of access comprise: availability, accessibility, accommodation, acceptability, and affordability. When blended with Maxwell's ${ }^{22}$ dimensions of health care quality (effectiveness, efficiency, equity, access, acceptability, and appropriateness) a more practical and workable version of access is provided that can be applied to any health care, including for those with learning disabilities. In summary, access may be defined as having six dimensions:

- Availability: the volume and type of services in the area

- Accessibility: the physical means by which the client reaches services (this can be both inter and intra building)
- Accommodation: how easy it is for the client to get 'through the door' (for example opening times, flexibility when making appointments)?

- Acceptability: the level of satisfaction expressed by the client

- Appropriate to need: is the service user obtaining what s/he requires from the profession?

- Affordability: the costs of the service, and ability to pay for it.

In a recent study with people with learning disabilities, this modified framework of access was used as a framework through which to view the data; $;^{23}$ the findings illustrated that dental care for people with learning disabilities varied greatly. While there was evidence of good practice under all six dimensions of access, there were also concerns expressed about: the attitudes of dental staff towards people with learning disabilities; the lack of collaboration between and within services; the lack of continuity of care and choice; and a failure to acknowledge that people with learning disabilities have the same rights to treatment as others. The research, from the perspective of participants and carers suggested that while policy and guidance is prescriptive and available, awareness among the dental and allied health professions is poor. Consequently care received by people with learning disabilities did not meet the aspirations of Valuing people and Valuing people's oral health., ${ }^{1,23}$ If we consider these findings alongside a predicted increase in the number of those with learning disabilities in the $\mathrm{UK}^{3}$ and the simultaneous establishment of specialist services, then the possibility is that existing unmet need is likely to increase. Recently, policy has sought to address healthcare inequalities experienced by people with learning disabilities by changing planning methods. ${ }^{9,24}$ Applying a bottom-up approach to dental services means that planning would start with the person, finding out their needs and preferences, and then fitting service delivery around the person, rather than utilising the present method of service delivery where the person has to 'fit' the services. This requires listening to people with learning disabilities to find out what they want from services and attempting to facilitate choice. However, part of facilitating choice for people with 
learning disabilities rests with PCOs. Using the described modified model of access as a commissioning tool for new contracts may ensure all areas of access are optimised, facilitating choice and inclusion, respecting individual rights and independence, and enabling an increase in quality care.

1. Department of Health. Valuing people. A new strategy for learning disability for the $21^{\text {st }}$ century. A White Paper. Cm 5086. London: The Stationery Office, 2001.

2. Department of Health. Valuing people's oral health. Gateway ref: 8660. London: Her Majesty's Stationery Office, 2007.

3. Institute for Health Research. Estimating future need/demand for supports for adults with learning disabilities in England. Lancaster University, 2004.

4. Gallagher J E, Fiske J. Special care dentistry: a professional challenge. Br Dent J 2007: 202: 619-629.

5. General Dental Council. Specialist Lists Review Group: final report. Item 14B. London: General Dental Council, 7 December 2005.

6. General Dental Council. 'GDC opens new specialist list in special care dentistry.' Press release. Available online http://www.gdc-uk.org/
News+publications+and+events/News+releases/GD C+opens+new+specialist+list+in+special+care+de ntistry.htm. Accessed 1/12/09.

7. Fiske J. Special care dentistry. Br Dent J 2006; 200: 61

8. Department of Health. 'NHS dental services in England: an independent review led by Professor Jimmy Steele.' London: Department of Health, 2009.

9. Department of Health. 'Choosing better oral health An oral health plan for England.' Gateway ref: 4790. London: Department of Health Publications, 2005.

10. World Health Organisation. 'The ICD-10 Classification of Mental and Behavioural Disorders'. Geneva WHO, 1992.

11. MacKenzie F. The roots of biomedical diagnosis. In Grant G, Goward P, Richardson M, Ramcharan $P$ (eds). Learning disability: a life cycle approach to valuing people. England, New York: Open University Press, 2005.

12. Dumbleton P. Words and numbers. Br J Learn Disabil 1998; 26: 151-153.

13. Hallberg U, Klingberg G. Giving low priority to oral health care. Voices from people with disabilities in a grounded theory study. Acta Odontol Scand 2004; 65: 265-270.

14. Davies K W, Holloway P J, Worthington H V. Dental treatment for mentally handicapped adults in general practice: parents and dentists' views. Community Dent Health 1988; 5: 381-387.

15. Nunn J H, Murray J J. Dental care of handicapped children by general dental practitioners. J Dent Educ 1988; 52: 463-465.

16. Luscre D M, Center D B. Procedures for reducing dental fear in children with autism. J Autism Dev Disord 1996; 26: 547-556.

17. The National Autistic Society: guidance for dental treatment. Available online: $h t t p: / / w w w . a u t i s m . o r g$ uk/nas/jsp/polopoly.jsp?d=1064\&ta=7844. Accessed 23/11/09.

18. Shakespeare T W. Disability rights and wrongs. London: Routledge. 2006.

19. Thomas C. Sociologies of disability and IIIness: contested ideas in disability studies and medical sociology. Basingstoke: Palgrave MacMillan, 2007.

20. Dougall A, Fiske J. Access to special care dentistry, part 1. Access. Br Dent J 2008; 204: 605-616.

21. Penchansky R, Thomas J W. The concept of access: definition and relationships to consumer satisfaction. Med Care 1981; 19: 127-140.

22. Maxwell R J. Quality assessment in health. Br Med J 1984; 288: 1470-1472

23. Owens J, Mistry K, Dyer T A. Access to dental services for people with learning disabilities: quality care? Submitted to J Disabil Oral Health, November 2009

24. Department of Health. Signposts for success; in commissioning and providing health services for people with learning disabilities. Cat. No. 98CC0156. 1998. 